\title{
Facilitated endoscopic beating heart coronary artery bypass grafting using a magnetic coupling device
}

\author{
Volkmar Falk, MD, $\mathrm{PhD}^{\mathrm{a}}$ \\ Thomas Walther, MD, $\mathrm{PhD}^{\mathrm{a}}$ \\ Hubert Stein, BSc, BME ${ }^{\mathrm{b}}$ \\ Stephan Jacobs, MDa \\ Claudia Walther, MD \\ Ardawahn Rastan, $\mathrm{MD}^{\mathrm{a}}$ \\ Gerhard Wimmer-Greinecker, MD, PhD ${ }^{\mathrm{d}}$ \\ Friedrich W. Mohr, MD, PhD ${ }^{\mathrm{a}}$
}

From the Department of Cardiac Surgery, Heartcenter, ${ }^{\mathrm{a}}$ University of Leipzig, Leipzig, Germany, Department of Clinical Development Engineering, ${ }^{\mathrm{b}}$ Intuitive Surgical, Sunnyvale, Calif, Department of Cardiology Heartcenter, ${ }^{c}$ University of Leipzig, Leipzig, Germany, and Department for Thoracic and Cardiovascular Surgery, ${ }^{\mathrm{d}}$ Johann Wolfgang Goethe University, Frankfurt, Germany.

Supported by Intuitive Surgical, Sunnyvale, Calif, and Ventrica, Fremont, Calif.

Received for publication Aug 20, 2002; revisions requested Sept 30, 2002; revisions received Nov 13, 2002; accepted for publication Jan 28, 2003.

Address for reprints: Volkmar Falk, MD, $\mathrm{PhD}$, Klinik für Herzchirurgie, Universität Leipzig Herzzentrum Strümpellstr. 39, 04289 Leipzig, Germany (E-mail: falv@medizin.uni-leipzig.de).

J Thorac Cardiovasc Surg 2003;126:1575-9

Copyright $(\odot) 2003$ by The American Association for Thoracic Surgery

$0022-5223 / 2003 \$ 30.00+0$

doi:10.1016/S0022-5223(03)00793-1
Background: Suturing of a coronary anastomosis in totally endoscopic coronary artery bypass grafting on the beating heart is technically demanding. The potential benefits of the endoscopic Magnetic Vascular Positioner device (Ventrica, Inc, Fremont, Calif) to facilitate construction of a coronary anastomosis in a closed chest environment were evaluated.

Methods: Totally endoscopic coronary artery bypass grafting on the beating heart was performed in 8 foxhound-beagle inbred dogs with the da Vinci telemanipulation system (Intuitive Surgical, Mountain View, Calif). A prototype of the endoscopic Magnetic Vascular Positioner device was used to facilitate construction of the coronary anastomosis. One pair of magnets was inserted in the internal thoracic artery and left anterior descending artery using robotic instruments to guide and place the endoscopic delivery platform. All animals underwent angiography; gross inspection of the anastomotic site was performed after excision of the hearts.

Results: The procedure was accomplished in all animals in 169 minutes (155-190 minutes). Dissection of the left anterior descending coronary artery (6.5 minutes; 1-20 minutes), positioning of the stabilizer (8.5 minutes; 7-16 minutes), placement of occlusion tapes (6 minutes, 3-10 minutes), and arteriotomy 5.5 minutes (3-30 minutes) was achieved without problems. By use of the Magnetic Vascular Positioner device, the anastomosis at the graft site was performed with the graft still in situ. Except for 1 premature deployment, all other deployments were easily accomplished in 3 minutes (1-28 minutes). The following adverse events were encountered: bleeding from the right ventricle caused by occlusion tape (1), anastomotic leakage on reperfusion requiring repair stitches (2), and anastomotic occlusion as a result of thrombus (1). All except 1 animal with a patent graft and anastomosis survived the procedure. The overall patency was 7 of 8 .

Discussion: The combination of robotic technology allowing for dexterous manipulation in a closed chest environment and a simple yet effective and timesaving technique for anastomotic coupling may facilitate beating heart totally endoscopic coronary artery bypass grafting.

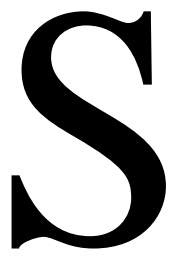

uturing of coronary bypass graft anastomosis has been a barrier to the evolution of totally endoscopic coronary artery bypass grafting (TECAB). The early Port-Access experience demonstrated that harvesting of a conduit is not the challenging part of a closed chest bypass graft procedure, and that construction of a coronary anastomosis is technically demanding and time consuming even on the arrested heart. ${ }^{1}$ With the introduction of telemanipulation systems that have over- 
come some of the limitations of conventional endoscopic instruments, TECAB has been performed consistently on the arrested and the beating heart. ${ }^{2-6}$ Although the total number of endoscopic internal thoracic artery (ITA) takedowns has continuously increased, the total number of successfully completed TECAB procedures is still small. Among the challenges are limited working space, indirect visualization, and the difficulty of maintaining insufflation. On the beating heart, the lack of effective stabilization and hemodynamic impairment complicate construction of a coronary anastomosis despite the enhanced endoscopic dexterity provided by contemporary telemanipulation systems. Only recently, a number of devices have been developed to facilitate construction of a distal graft to coronary anastomosis. ${ }^{7}$ To evaluate the potential synergistic effect of these new technologies, an endoscopic beating heart canine study was performed using the prototype of an endoscopic magnetic vascular positioning device to facilitate the construction of a distal graft to coronary anastomosis.

\section{Methods}

After approval of the study by the governmental offices (Regierungspräsidium), 8 foxhound-beagle inbred dogs $(30-40 \mathrm{~kg}$ ) underwent operations. Premedication included levomethadonechloride $(0.3 \mathrm{mg} / \mathrm{kg}$ intramuscularly [IM]), atropine $(0.02 \mathrm{mg} / \mathrm{kg}$ IM), ketamine (3 mg/kg IM), and xylazinhydrochloride $(0.7 \mathrm{mg} / \mathrm{kg}$ IM). After induction with ketamine (10 $\mathrm{mg} / \mathrm{kg}$ intravenously [IV]) and diazepam $(0.5 \mathrm{mg} / \mathrm{kg} \mathrm{IV})$, endotracheal intubation was performed. Pancuronium was administered at a dose of $0.13 \mathrm{mg} / \mathrm{kg}$ IV. Inhalational anesthesia was maintained with isoflurane $1.5 \%$ to $2.5 \%$ in oxygen, fentanyl was administered at a dose of $25 \mu \mathrm{g} \cdot \mathrm{kg}$ $\cdot \mathrm{h}$, and midazolam was administered at a dose of $0.2 \mathrm{mg} \cdot \mathrm{kg} \cdot \mathrm{h}$ continuously. Amiodarone $(150 \mathrm{mg})$ was administered to prevent arrhythmias, and acetylsalicylate (500 mg IV) was used for antiplatelet therapy. An arterial line was placed in the right femoral artery, and a central venous line was placed in the right jugular vein. The animals were placed in the right lateral decubitus position. Monitoring included electrocardiography, arterial blood pressure, central venous pressure, and oxygen saturation. Intermittent positive-pressure ventilation was used. Normal saline solution was administered at a maintenance dose of 10 to $20 \mathrm{~mL} \cdot \mathrm{kg} \cdot \mathrm{h}$. Volume boluses and dopamine infusion were given as needed. The da Vinci telemanipulation system (Intuitive Surgical, Mountain View, Calif) has been described in detail elsewhere. ${ }^{2,3}$ A vacuumassisted endoscopic stabilizer including an irrigation channel was used (Intuitive, not approved by the Food and Drug Administration). The surgical approach has been described. ${ }^{8}$ In brief, the entire operation was performed through a total of 5 thoracoscopic ports for the left ( $8 \mathrm{~mm}$ midaxillary seventh intercostal space) and right instruments ( $8 \mathrm{~mm}$ midaxillary third intercostal space), the scope (12 mm midaxillary fifth intercostal space), the stabilizer (12 $\mathrm{mm}$ subxiphoid), and the coupling device (12 mm fourth or sixth intercostal space below the midaxillary line).

Carbon dioxide insufflation was not applied. Motion scaling was set to $3: 1$. A $30^{\circ}$ scope was used angled up for manipulation of the ITA and angled down when working on the heart. The endoscopic Magnetic Vascular Positioner (MVP) System (Ventrica, Inc, Fremont, Calif) consists of 4 magnetic implants and a delivery system. The external measurements of the magnets used in this study were $6.8 \mathrm{~mm}$ and $2.3 \mathrm{~mm}$ on the major and minor axes, respectively, with internal dimensions of $4.0 \mathrm{~mm}$ and $1.4 \mathrm{~mm}$ on the major and minor axes, respectively. The resulting orifice area was $6.0 \mathrm{~mm}^{2}$.

The magnets were $0.4 \mathrm{~mm}$ thick. One pair of elliptical magnets created an anastomotic port in the graft and the coronary artery, respectively. One magnet of each pair was placed within the vessel lumen at the incision site (intravascular magnetic implant), and the other was held in place on the external surface of the vessel (extravascular magnetic implant) by magnetic attraction. The 2 ports were connected by magnetic force and formed a side-to-side (functional end-to-side) anastomosis.

The left ITA was harvested, and the most distal portion was skeletonized. The pericardium was opened, and the left anterior descending (LAD) coronary artery was identified. Heparin (100 U/kg IV) was administered, and the activated clotting time was maintained at greater than 300 seconds. The ITA was occluded using a vascular occluder (Scanlan, St Paul, Minn). The distal end was clipped. A sharp arteriotomy of 3 to $3.5 \mathrm{~mm}$ in length was made in the distal portion of the ITA, and the magnetic vascular coupling device was inserted. For this study, the prototype of a cable-mounted endoscopic delivery system with an external trigger was used (Figure 1). The device was grabbed with robotic instruments, and the intravascular implant was guided into the target vessel. On correct seating of the internal magnet, the external magnet was released.

The target site (mid-portion of the LAD artery between the first and second collateral branch) was then immobilized by the vacuum-assisted stabilizer, which was inserted through a subxiphoid port. The LAD artery was occluded proximally and distally to the anastomotic site using 2 self-locking silicone rubber bands (Intuitive). A 3 to $3.5 \mathrm{~mm}$ arteriotomy was made in the LAD artery. Directed irrigation of the operating field was provided through a separate channel of the stabilizer. A second pair of magnets was then introduced and placed in the LAD artery using robotic instruments (Figure 2). The anastomosis was completed by detaching the ITA from the chest wall and connecting the outer magnets of the graft and the target vessel, respectively (Figure 3 ). The silicone occlusion tapes were released, and all instruments were withdrawn. After the procedure, all animals underwent angiography using a fluoroscopy unit (Sieremobil 2000; Siemens, Munich, Germany), after which they were killed. Because of the radiopaque nature of the magnets, quantitative angiographic analysis was not possible. Graft flow was assessed in 3 angles: anteroposterior, left anterior oblique, and right anterior oblique. After angiographic control, flow measurements were performed through a lateral thoracotomy. Postmortem gross inspection of the anastomotic site was performed after excision of the hearts. End points of the study were the technical feasibility of the construction of a magnetic port anastomosis, anastomotic patency (qualitatively), anastomotic construction time, and graft flows post-anastomosis.

All animals received humane care in compliance with the "Principles of Laboratory Animal Care" formulated by the National Society of Medical Research and the "Guide for the Care and Use of Laboratory Animals" prepared by the Institute of 


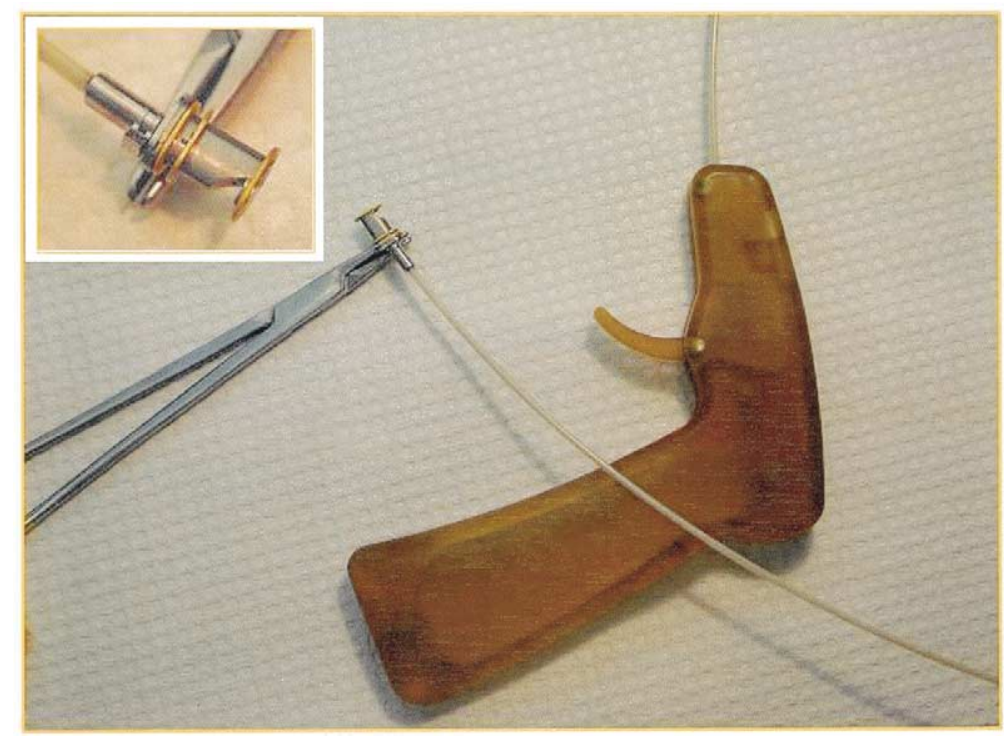

Figure 1. Endoscopic cable-driven delivery system for the magnetic ports.

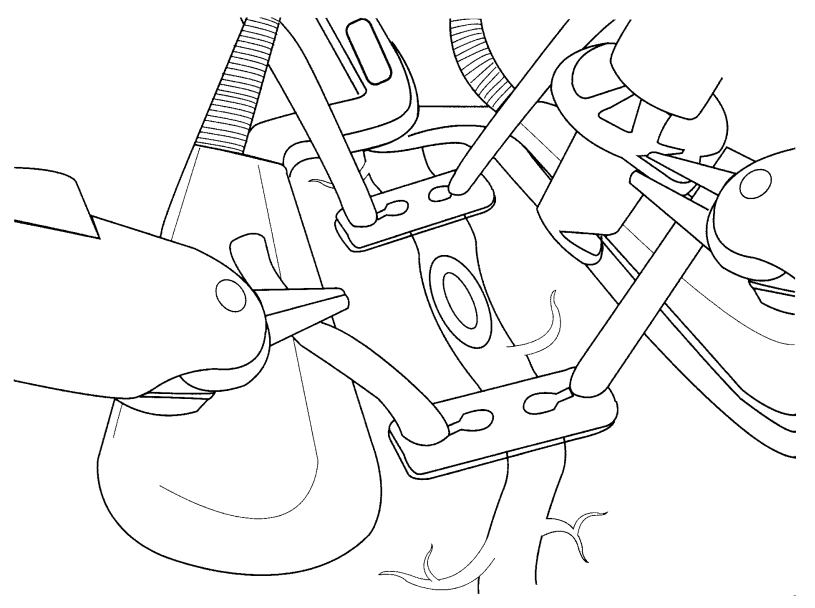

Figure 2. Robotically guided placement of magnets into the LAD coronary artery. The delivery system is inserted through a port and grabbed with "wristed" instruments. Once the inner magnet is placed in the LAD artery, the outer magnet is released by external actuation.

Laboratory Animal Resources, National Research Council, and published by the National Academy Press, revised 1996. All data are presented as median and range.

\section{Results}

The procedure including placement of the magnets and construction of a graft to coronary connection was accomplished in all animals in 169 minutes (155-190 minutes). ITA takedown was completed in 44 minutes (32-67 minutes). The time for skeletonization of the most distal portion of the vessel, distal ITA occlusion by clips, and placement

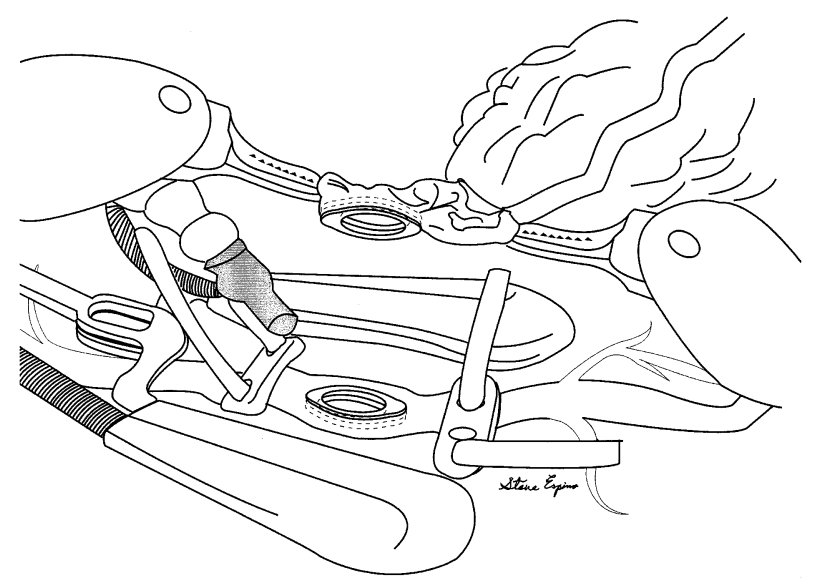

Figure 3. The graft is connected to the coronary by 2 pairs of magnets.

of bulldog clamps for temporary proximal vascular occlusion was 23 minutes (16-35 minutes). The lack of countertraction and inefficiency of the clamps used were responsible for some delays during this part of the operation. Pericardiotomy and identification of the LAD coronary artery was readily accomplished in all animals (7.5 minutes; 3-10 minutes). LAD coronary artery dissection using a blunt knife (6.5 minutes; 1-20 minutes), positioning of the stabilizer including creation of a subxiphoid port (8.5 minutes; 7-16 minutes), and placement of the silicone rubber occlusion tapes proximally and distally of the target site (6 minutes, 3-10 minutes) were achieved without problems, except for $1 \mathrm{dog}$ in which the occlusion tape caused bleeding from the right ventricle that required repair stitches. The 
TABLE 1. Angiographic and morphologic findings at anastomotic site

\begin{tabular}{|c|c|c|c|}
\hline $\begin{array}{l}\text { Animal } \\
\text { no. }\end{array}$ & Survival & Angiographic result & $\begin{array}{l}\text { Gross inspection of } \\
\text { anastomotic site }\end{array}$ \\
\hline 1 & Yes & Patent good run-off & No excess tissue \\
\hline 2 & Yes & Patent good run-off & No excess tissue \\
\hline 3 & Yes & Patent good run-off & No excess tissue \\
\hline 4 & Yes & Occluded & $\begin{array}{l}\text { Thrombus at } \\
\text { anastomotic site, } \\
\text { no excess tissue }\end{array}$ \\
\hline 5 & Yes & Patent medium run-off & No excess tissue \\
\hline 6 & Yes & Patent good run-off & No excess tissue \\
\hline 7 & No & $\begin{array}{l}\text { Patent (postmortem } \\
\text { angio) }\end{array}$ & $\begin{array}{l}\text { No excess tissue, } \\
\text { no thrombus } \\
\text { Cause of death } \\
\text { unresolved }\end{array}$ \\
\hline 8 & Yes & $\begin{array}{l}\text { Patent, medium run-off } \\
\text { (D2) }\end{array}$ & No excess tissue \\
\hline
\end{tabular}

time for arteriotomy was 5.5 minutes (3-30 minutes). In 1 case, the incision was too long to accommodate the magnets. A second arteriotomy was subsequently performed more distally on the LAD artery but again was not sufficient to allow for correct placement of the device. After occlusion of the LAD artery, a third arteriotomy was then made in the second collateral branch after temporary occlusion (animal 8 ). Although the second collateral branch was even smaller than the LAD artery, an anastomosis could be performed. The MVP anastomosis at the graft site was performed with the graft still attached to the chest wall to provide some counter traction. Except for 1 premature deployment of the outer magnet that required removal of the magnets, a new arteriotomy, and redeployment (animal 6), all other deployments were easily accomplished (3 minutes; 1-28 minutes). The time for deployment on the LAD artery was 3 minutes (1-9 minutes). In 1 animal, the outer magnet was released before optimal alignment was achieved. As a consequence, not enough tissue was caught between the magnets, causing leakage on reperfusion that required some repair stitches (animal 3). Qualitative angiographic data and the results of gross inspection of the anastomosis are summarized in Table 1. Graft flows were in the range of 18 to $35 \mathrm{~mL} / \mathrm{min}$. All animals except 1 (which suddenly died on reperfusion but had a patent graft) survived the procedure.

\section{Discussion}

This study demonstrates the feasibility of an endoscopic beating heart bypass procedure using a magnetic anastomotic connector for the distal anastomosis. The MVP device used in this trial was a prototype with a cable-driven external trigger that has been found easier to use than an internal actuation system used earlier on bench tests. Placement of the internal magnets was achieved with robotic instruments that also stabilized the delivery platform during activation of the release mechanism. In all animals, an anastomosis could be created on the beating heart and in short anastomotic times. Although the time for LAD coronary artery dissection, placement of vascular occlusion tapes, and arteriotomy is essentially the same as for the standard endoscopic sutured anastomotic technique, the time-consuming part of suturing that adds substantially to the total ischemic time (up to 30 minutes) could be eliminated. Compared with ischemic times reported for TECAB or LAD coronary artery occlusion times in beating heart $\mathrm{TECAB}^{9}$, the use of this magnetic anastomotic coupling device shortens the time necessary to construct an endoscopic graft to coronary anastomosis.

Endoscopic handling of the magnets was hampered in some cases by the lack of titanium instruments and inadvertent magnetic attraction to the da Vinci instruments or the stabilizer. This issue can be easily resolved by using nonmagnetic materials for manufacturing of endoscopic instruments. Creation of an ideal incision in the graft or coronary that avoids excess tissue inside the lumen but also leaves enough tissue to include in between magnets requires some skill and experience. If the arteriotomy is too wide, the resulting leakage may require conversion to a suturing technique. In this study, repair stitches were necessary in 2 animals to close a leakage caused by incomplete tissue capture between magnets. With smaller magnets or a different, more forgiving connector design, this problem may be addressed in the future.

In 1 animal, a thrombus was found at the site of the anastomosis. Although this is to be considered an adverse event, it has to be emphasized that the antiplatelet regimen used in this study was different from what has been recommended by the manufacturer and includes the preoperative administration of clopidogrel and acetylsalicylate. In addition, unlike the implants that have recently been used in other animal studies and a human trial, the prototypes used in this study were smaller (to adjust for the small coronary arteries of dogs) and had a different subcoating (no gold). The blood contact surface of the implants was made of a medical-grade polymer. The effect of the polymer on patency with the device to date has been shown in acute and chronic animal testing. In a pig model of left ITA to LAD coronary artery grafting, angiographic assessment at 1 week and 1 month showed a patency rate of $100 \%$ (35/35) and 97\% (33/34), respectively. Histologic studies as late as 6 months have demonstrated complete neointimal coverage of the magnets without luminal narrowing.*

The limitations of manual control and tracking were outlined in a recent review. ${ }^{10}$ In addition to the human

*Filsoufi F, Farivar RS, Aklog L, Anderson CA, Chen RH, Lichtenstein S, et al. Automated distal coronary bypass using a novel magnetic coupler (MVP). Unpublished data. 
factors that set the limits of surgical performance, the use of a telemanipulation system leads to additional delays in response time and decreases the geometric accuracy of the operator. ${ }^{11}$ This has been demonstrated by comparing manually and robotically constructed anastomoses. ${ }^{12}$ Although this difference may not be clinically relevant on the arrested heart, system-related prolongation of motor response caused by mechanical inertia, electronic, and optic delays may render endoscopic suturing on the beating heart inaccurate. By using a standardized coupling device, some of the difficulties of constructing an anastomosis remotely can be eliminated.

Given the good patency results with the MVP reported for the first experimental and clinical trials, ${ }^{13} *$ it seems justified to conclude that the combination of robotic technology allowing for dexterous manipulation in a closed chest environment and a simple yet effective and timesaving technique for anastomotic coupling may facilitate endoscopic beating heart bypass grafting and accelerate the adoption of this procedure.

We thank Darin Gittings and Florian Ludwig from Ventrica Inc for their technical support during the study.

\section{References}

1. Stevens JH, Burdon TA, Siegel LC, Peters WS, Pompili MF, St Goar FG, et al. Port-access coronary artery bypass with cardioplegic arrest: acute and chronic canine studies. Ann Thorac Surg. 1997;62:435-40.

2. Falk V, Diegeler A, Walther T, Bannusch J, Bucerius J, Raumans J, et

*Filsoufi F, Farivar RS, Aklog L, Anderson CA, Chen RH, Lichtenstein S, et al. Automated distal coronary bypass using a novel magnetic coupler (MVP). Unpublished data. al. Total endoscopic coronary artery bypass grafting. Eur J Cardiothorac Surg. 2000;17:38-45.

3. Dogan S, Aybek T, Andresen E, Byhahn C, Mierdl S, Wetpahl K, et al. Totally endoscopic coronary artery bypass grafting on cardiopulmonary bypass with robotically enhanced telemanipulation: report of forty five cases. $J$ Thorac Cardiovasc Surg. 2002;123:1125-31.

4. Kappert U, Cichon R, Schneider J, Gulielmos V, Tugtekin SM, Matschke K, et al. Closed chest coronary artery bypass surgery on the beating heart with the use of a robotic system. $J$ Thorac Cardiovasc Surg. 2000;120:809-11.

5. Falk V, Diegeler A, Walther T, Jacobs S, Raumans J, Mohr FW. Total endoscopic off-pump coronary artery bypass grafting. Heart Surg Forum. 2000;3:29-31.

6. Boyd WD, Rayman R, Desai ND, Menkis AH, Dobkowski W, Ganapathy $\mathrm{S}$, et al. Closed-chest coronary artery bypass grafting on the beating heart with the use of a computer-enhanced surgical robotic system. J Thorac Cardiovasc Surg. 2000;120:807-9.

7. Subramanian VA, Fonger JD, Connolly MW. Facilitated vascular anastomosis in coronary bypass surgery. Semin Thorac Cardiovasc Surg. 2002;14:89-100.

8. Falk V, Fann JI, Grünenfelder J, Daunt D, Burdon TA. Total endoscopic computer enhanced beating heart coronary artery bypass grafting. Ann Thorac Surg. 2000;70:2029-33.

9. Boyd WD, Kodera K, Stahl KD, Rayman R. Current status and future directions in computer-enhanced and video- and robotic-assisted coronary bypass surgery. Semin Thorac Cardiovas Surg. 2002;14:101-9.

10. Falk V. Manual control and tracking-a human factor analysis relevant for beating heart surgery. Ann Thorac Surg. 2002;74:624-8.

11. Jacobs S, Holzhey D, Strauss G, Ullmann C, Walther T, Mohr FW, et al. Limitations for manual and telemanipulator assisted motion tracking for endoscopic beating heart surgery. Thorac Cardiovasc Surg. 2002;50(Suppl 1):S73.

12. Arnold M, Boehm DH, Welsch U, Detter C, Reichart B, Reichenspurner $\mathrm{H}$. Evaluation of acute traumatic changes of the coronary artery wall after robotically assisted endoscopic coronary artery bypass grafting. Heart Surg Forum. 2002;5:128-31.

13. Klima U, Falk V, Maringka M, Bargenda S, Badack S, Moritz A, et al. Magnetic vascular coupling for distal anastomosis in coronary artery bypass grafting: a multicenter trial. $J$ Thorac Cardiovasc Surg. 2003; 126:1568-74. 